\title{
The role of chemoprevention by selective cyclooxygenase-2 inhibitors in colorectal cancer patients - a population-based study
}

\author{
Yi-Hsin Yang ${ }^{1,2}$, Yea-Huei Kao Yang ${ }^{3 *}$, Ching-Lan Cheng ${ }^{3}$, Pei-Shan $\mathrm{Ho}^{2,4}$ and Ying-Chin $\mathrm{Ko}^{5,6,7}$
}

\begin{abstract}
Background: There are limited population-based studies focusing on the chemopreventive effects of selective cyclooxygenase-2 (COX-2) inhibitors against colorectal cancer. The purpose of this study is to assess the trends and dose-response effects of various medication possession ratios (MPR) of selective COX-2 inhibitor used for chemoprevention of colorectal cancer.

Methods: A population-based case-control study was conducted using the Taiwan Health Insurance Research Database (NHIRD). The study comprised 21,460 colorectal cancer patients and 79,331 controls. The conditional logistic regression was applied to estimate the odds ratios (ORs) for COX-2 inhibitors used for several durations (5 years, 3 years, 1 year, 6 months and 3 months) prior to the index date.

Results: In patients receiving selective COX-2 inhibitors, the OR was 0.51 ( $95 \% \mathrm{Cl}=0.29 \sim 0.90, \mathrm{p}=0.021$ ) for an estimated 5 -year period in developing colorectal cancer. ORs showing significant protection effects were found in $10 \%$ of MPRs for 5-year, 3-year, and 1-year usage. Risk reduction against colorectal cancer by selective COX-2 inhibitors was observed as early as 6 months after usage.

Conclusion: Our results indicate that selective COX-2 inhibitors may reduce the development of colorectal cancer by at least $10 \%$ based on the MPRs evaluated. Given the limited number of clinical reports from general populations, our results add to the knowledge of chemopreventive effects of selective COX-2 inhibitors against cancer in individuals at no increased risk of colorectal cancer.
\end{abstract}

Keywords: Chemoprevention, Colorectal cancer, Selective COX-2 inhibitor, Population-based study

\section{Background}

Colorectal cancer (CRC) is currently a common cancer in many countries [1]. In Taiwan it is the second leading cause of cancer-related death, with a 5-year survival rate of $56 \%$ and a median age of 68 years [2]. The incidence of CRC is a global health problem, and the search for chemopreventive agents to inhibit its carcinogenesis is urgently required.

Cyclooxygenase-2 (COX-2) has been found to be overexpressed in a number of cancers, including CRC, and has been shown to stimulate tumorigenic pathways $[3,4]$. Therefore, COX-2 is a valid target for inhibiting or

\footnotetext{
*Correspondence: yhkao@mail.ncku.edu.tw

${ }^{3}$ Institute of Clinical Pharmacy and Pharmaceutical Sciences, Health Outcome Research Center, National Cheng Kung University, Tainan, Taiwan

Full list of author information is available at the end of the article
}

preventing carcinogenesis [3,5]. Non-steroidal antiinflammatory drugs (NSAIDs) inhibit both isoforms of cyclooxygenase (COX-1 and COX-2). In the gastrointestinal tract, COX-1 produces prostanoids that are involved in the defense and repair of the gastrointestinal mucosa, while COX-2 is expressed in response to inflammatory stimulation [3]. Variation in the chemical structure of existing NSAIDs results in different specificities for COX-1 and COX-2 [6]. Traditional NSAIDs, such as aspirin, are generally less selective for COX-2, whereas Coxibs (celecoxib, rofecoxib) have higher COX-2 selectivity. Given the different roles of COX enzymes in the gastrointestinal tract, selective COX-2 inhibitors have been shown to have less gastrointestinal toxicity than traditional NSAIDs [4].

\section{Biomed Central}


Most clinical studies investigating the chemopreventive role of selective COX-2 inhibitors have been conducted in Western populations [7]. Therefore, it is of interest to conduct similar population-based studies in an Asian population so that comparisons among demographic groups can be made. The Taiwan Health Insurance Research Database (NHIRD) contains all health insurance claims made in the Taiwanese population, serving as a useful resource to conduct this type of population-based study.

The purpose of this study is to assess the trends and dose-response effects of various medication possession ratios (MPR) for selective COX-2 inhibitor usage in chemoprevention of CRC. Furthermore, subgroups of gender and age categories are compared.

\section{Methods}

\section{Data source}

The National Health Insurance (NHI) program was initiated in 1995 and covers all medical services in Taiwan. The coverage of the NHI program was initially $93.1 \%$ of the entire Taiwanese population in 1996, rising to $99.6 \%$ by 2010. The program's National Health Insurance Research Database (NHIRD) contains inpatient and outpatient medical and prescription drug claims as well as the demographic data of all beneficiaries. We used two sets of data from the NHIRD in this study to construct our case and control groups. This ethics of using the database and the study design was reviewed and approved by the Institutional Review Board of Kaohsiung Medical University Hospital (KMUH-IRB-980174).

\section{Case group}

We retrieved an 11-year longitudinal database (19972007 ) of patients who have at least one diagnosis of ICD 9 (International Classification of Diseases revision 9 code 140-208) from the NHIRD. This database includes records of inpatients, outpatients and pharmaceuticals. As these patients were reported in the NHI database for cancer screening purposes, the actual CRC patients could be identified by linking their encrypted personal identification number to the Registry for Catastrophic Illness patients with ICD 9 code 153-154. The date of first diagnosis was considered the index date for each patient.

For the period 2002-2006, we identified 42,358 CRC patients from the database. For the same period, the number of cancer cases reported by the Taiwan Cancer Registry was 46,432 across all ages [2]. Thus, the patients we identified accounted for $91 \%$ of the total Cancer Registry patients. We excluded patients whose age was not between 18 and 100 years old or who were diagnosed with other cancers (ICD 9 code 140-208, except 153-154) or benign lesions (ICD 9 code 210-239) prior to the index date.

\section{Control}

We selected controls from the Longitudinal Health Insurance Database 2005 (LHID2005, years 1996-2006). The LHID2005 contains all the original claims of $1,000,000$ beneficiaries, randomly sampled from the Registry for Beneficiaries (ID) of the NHI database in 2005. According to the NHIRD report, there was no significant demographical difference between the patients in the LHID2005 and the whole National Health Insurance database. At most, 10 randomly selected controls, without any history of cancer (ICD9 code 140-208) or benign neoplasm (ICD9 code 210-239), were matched with each CRC patient in terms of gender and birth year. The index date of each CRC patient was assigned as the index date to each of the matched controls.

\section{Drug categories and dosage}

The selectivity of a given NSAID can be expressed by the COX-1/COX-2 IC50 ratio. Drugs which are more selective for COX-2, such as coxibs, have lower IC50 ratios than traditional NSAIDs [8]. Selective COX-2 inhibitors (celecoxib and rofecoxib) became eligible for reimbursement by the NHI program starting in 2001. Rofecoxib was withdrawn from the market in 2004, therefore celecoxib is the only currently recorded selective COX-2 inhibitor in the NHIRD. In addition to selective COX-2 inhibitors, we used data from patients using traditional NSAIDs (indomethacin, sulindac, diclofenac, acemetacin, ketorolac, piroxicam, ibuprofen, naproxen, ketoprofen and mefenamic acid) and preferential COX-2 inhibitors (nabumetone, meloxicam, etodolac and nimesulide) as covariates in statistical analyses.

We determined patient usage of the three prescribed drug types (selective COX-2 inhibitors, traditional NSAIDs and preferential COX-2 inhibitors) from data obtained by the Details of Inpatient Orders (DO) and Details of Ambulatory Care Orders (OO) from the Original Claim Database. Information obtained included delivery dates, number of tablets, capsules or other dispensation vehicles, drug dosage, and duration of the prescription period. We used all prescriptions of oral traditional NSAIDs, selective COX-2 inhibitors and preferential COX-2 inhibitors filled during the follow-up period as independent variables in our statistical analyses. The defined daily dosage (DDD), which is the average dosage of a drug taken by adults for the most frequent indication, was computed according to the anatomic therapeutic chemical (ATC) classification system from WHO [9].

\section{Follow-up groups}

We created three follow-up groups of different durations (all beginning in 1997) to ensure each patient had the same observation period, and to maximize the number 
of subjects for our analysis. The 5-year follow-up group had patients with full 5-year observation records before their index date, and hence, only cancer patients with their first diagnosis between 2002 and 2006 were included (Figure 1). Similarly, for the 3-year and 1-year follow-up groups, cancer patients with their first diagnosis between 2000 and 2006 and between 1998 and 2006, respectively, were included. We used the 1-year followup group to obtain data regarding patients that used the drugs for 3 and 6 months.

\section{Statistical analysis}

Each CRC patient and the corresponding matched controls were considered as a stratum in the matched casecontrol study. During variable analysis between cases and controls, each case was matched with 10 controls. We used the reciprocals of the values in the control group and applied them as weights in the estimates and hypothesis testing.

We used conditional logistic regression to determine the estimated drug effects, as determined by their odds ratios (ORs) and 95\% confidence intervals (CI), of selective COX-2 inhibitors used over different durations (5 years, 3 years, 1 year, 6 months and 3 months). The medication possession ratios (MPRs) of the inhibitors, calculated by dividing the cumulative DDD by the total number of days in each follow-up period, were used as a continuous independent variable.

The MPRs of selective COX-2 inhibitors were ordered in increments of $10 \%$ with $10 \%$ and $90 \%$ as cut-off points. For subjects with an MPR of $10 \%, 50 \%$, or $90 \%$, we generated three categorical variables for each: subjects taking the drug for at least $50 \%$ of their follow-up period; subjects taking the drug for less than $50 \%$ of the

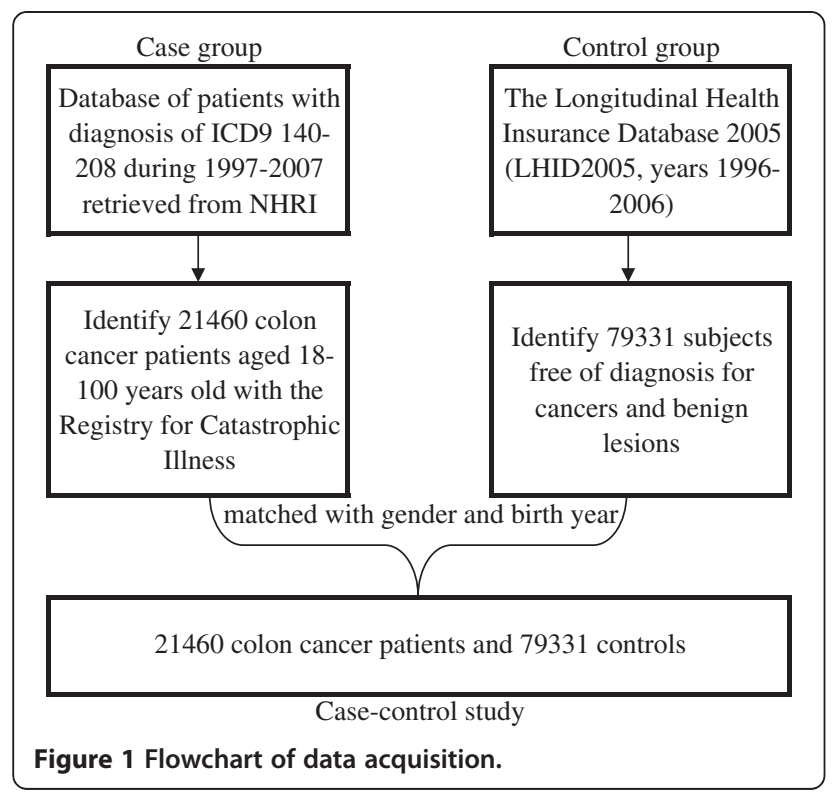

time; and non-users (the reference group). In total, nine separate conditional logistic models were generated for these three MPRs.

In addition to the variables calculated for selective COX-2 inhibitors, we added the following covariates into the conditional logistic regression analysis models: 1) MPRs of traditional NSAIDs and preferential COX-2 inhibitors; 2) three categories of insured payroll claims; 3) five different residential areas; and 4) comorbidities with dichotomous variables for 15 medical conditions. We used the ICD 9 codes specified in the Charlson comorbidity index $[10,11]$ for the 15 diseases were used to define diseases that were present within the same duration of cumulative DDD before the index dates. Any recorded diagnosis in inpatient or outpatient records would be considered as having diseases.

\section{Sensitivity analysis}

Sensitivity analyses were conducted in this study with a series of 5-, 3- and 1-year follow-up groups. The use of selective COX-2 inhibitors can have various side effects, including congestive heart failure or cardiovascular disorders. We also conducted separate analyses on participants without any occurrence of myocardial infarction or congestive heart failure, without any occurrence of peptic ulcer disease, and without any occurrence of colon or rectal polyps. For patients with occurrence of diseases, only patients with peptic ulcer disease had sufficient sample size for conditional logistic regressions.

\section{Results}

The study database of the 5-year follow-up group comprised 21,460 cases and 79,331 controls. The basic characteristics for the 5-year follow-up groups are shown in Table 1. At the index dates, the average ( \pm sd, standard deviation) age of subjects in the group of 65-100 year olds was $75.20( \pm 6.67)$ years, and in the group of 18-64 year olds it was $52.45( \pm 9.21)$ years. Characteristics regarding basic information and potential confounding variables are given in Table 1. For prevalence rates of comorbidity, the prior 5-year prevalence rates of congestive heart failure ( $8.7 \%$ vs. $7.5 \%)$, peptic ulcer disease (37.2\% vs. $27.6 \%)$, mild liver disease (19.1\% vs. $15.5 \%)$, diabetes $(22.6 \%$ vs. $19.0 \%)$ and renal disease $(8.5 \%$ vs. $7.2 \%)$ were significantly higher in the CRC group, and the prevalence of dementia was higher in the control group. The proportions of having at least one prescription in the prior 5 years for selective COX-2 inhibitors were not significantly different $(\mathrm{p}=0.595)$; however, the average cumulative defined daily dose (DDD) differed significantly between CRC patients and controls (78.0 \pm 151.1 vs. $85.5 \pm 120.5, \mathrm{p}=0.010$ ).

The estimated effects (odds ratios, ORs) of drug usages in various durations (5-year, 3-year, 1 year, 6 months and 
Table 1 Basic characteristics among patients and controls

\begin{tabular}{|c|c|c|c|c|c|c|}
\hline \multirow[b]{2}{*}{ Variable } & \multirow[b]{2}{*}{ Item } & \multicolumn{2}{|c|}{ Cancer patients } & \multicolumn{3}{|c|}{ Controls } \\
\hline & & $n$ & $\%$ & $n^{a}$ & $\%^{a}$ & $\mathrm{p}$-value \\
\hline total & & 21460 & & 79331 & & \\
\hline \multicolumn{7}{|l|}{$\operatorname{sex}$} \\
\hline & male & 12882 & 60.0 & 47621 & 60.0 & \\
\hline & female & 8578 & 40.0 & 31710 & 40.0 & \\
\hline \multicolumn{7}{|c|}{ age group } \\
\hline & 18-64 years old & 9072 & 42.3 & 33536 & 42.3 & \\
\hline & 65-100 years old & 12388 & 57.7 & 45795 & 57.7 & \\
\hline \multicolumn{7}{|c|}{ income category } \\
\hline & not working & 6958 & 32.4 & 23361 & 29.4 & $<.001$ \\
\hline & monthly income $<=$ NT\$20000 & 11019 & 51.3 & 45805 & 57.7 & \\
\hline & monthly income> NT\$20000 & 3483 & 16.2 & 10165 & 12.8 & \\
\hline \multicolumn{7}{|c|}{ comorbidity in 5 years before index date } \\
\hline & Myocardial infarction & 486 & 2.3 & 1784 & 2.2 & 0.888 \\
\hline & Congestive heart failure & 1864 & 8.7 & 5917 & 7.5 & $<.001$ \\
\hline & Peripheral vascular disease & 609 & 2.8 & 2315 & 2.9 & 0.534 \\
\hline & Cerebrovascular disease & 3724 & 17.4 & 13514 & 17.0 & 0.273 \\
\hline & Dementia & 655 & 3.1 & 2825 & 3.6 & $<.001$ \\
\hline & Chronic pulmonary disease & 7002 & 32.6 & 25707 & 32.4 & 0.534 \\
\hline & Rheumatologic disease & 692 & 3.2 & 2552 & 3.2 & 0.957 \\
\hline & Peptic ulcer disease & 7974 & 37.2 & 21875 & 27.6 & $<.001$ \\
\hline & Mild liver disease & 4092 & 19.1 & 12302 & 15.5 & $<.001$ \\
\hline & Diabetes & 4853 & 22.6 & 15049 & 19.0 & $<.001$ \\
\hline & Diabetes with chronic complications & 1462 & 6.8 & 4589 & 5.8 & $<.001$ \\
\hline & Hemiplegia or paraplegia & 416 & 1.9 & 1609 & 2.0 & 0.408 \\
\hline & Renal disease & 1833 & 8.5 & 5734 & 7.2 & $<.001$ \\
\hline & Moderate or severe liver disease & 94 & 0.4 & 298 & 0.4 & 0.191 \\
\hline \multicolumn{7}{|c|}{ selective COX-2 inhibitors } \\
\hline & No & 18872 & 87.9 & 69896 & 88.1 & 0.504 \\
\hline & Yes & 2588 & 12.1 & 9435 & 11.9 & \\
\hline & Average $( \pm$ sd) DDD & \multicolumn{2}{|c|}{$78.0( \pm 151.1)$} & \multicolumn{2}{|c|}{$85.5( \pm 231.7)$} & $0.014^{b}$ \\
\hline \multicolumn{7}{|l|}{ tNSAID } \\
\hline & No & 2014 & 9.4 & 8517 & 10.7 & $<.001$ \\
\hline & Yes & 19446 & 90.6 & 70814 & 89.3 & \\
\hline & Average $( \pm s d)$ DDD & \multicolumn{2}{|c|}{$87.2( \pm 145.8)$} & \multicolumn{2}{|c|}{$94.5( \pm 170.0)$} & $0.001^{b}$ \\
\hline \multicolumn{7}{|c|}{ preferential COX-2 inhibitors } \\
\hline & No & 15681 & 73.1 & 57451 & 72.4 & 0.058 \\
\hline & Yes & 5779 & 26.9 & 21880 & 27.6 & \\
\hline & Average $( \pm \mathrm{sd}) \mathrm{DDD}$ & \multicolumn{2}{|c|}{$61.6( \pm 121.9)$} & \multicolumn{2}{|c|}{$62.2(144.6)$} & $0.278^{b}$ \\
\hline
\end{tabular}

a: weighted according to the matched sizes of cases.

b: Two-sample t-tests were conducted at the natural logarithm of average DDD.

DDD: define daily dose; NT: new taiwan dollar; sd: standard deviation; tNSAID: traditional NSAID.

3 months) prior to the index dates were investigated by separate conditional logistic regressions with MPR of selective COX-2 inhibitors as a continuous independent variable together with covariates (Table 2). The analyses were conducted in the total subject group and also subgroups of age (age $>=65$, age $<65$ ) and gender (males, females). It was estimated that for people taking selective COX-2 inhibitors for the whole 5 years prior to the index date the OR was $0.51 \quad(95 \% \mathrm{CI}=0.29 \sim 0.90$, $\mathrm{p}=0.021)$ for developing $\mathrm{CRC}$, and the $\mathrm{OR}$ was smaller (0.36, 95\% CI $=0.08 \sim 1.67, \mathrm{p}=0.193)$ in people aged less than 65 , and was larger $(0.57,95 \% \mathrm{CI}=0.31 \sim 1.07$, 
Table 2 Estimated odds ratios for taking selective COX-2 Inhibitors during various prior duration

\begin{tabular}{|c|c|c|c|c|c|c|c|}
\hline \multirow{2}{*}{$\begin{array}{l}\text { Duration } \\
\text { prior to } \\
\text { index date }\end{array}$} & \multicolumn{2}{|c|}{ Colon cancer patients } & \multicolumn{2}{|c|}{ Controls } & \multirow{2}{*}{$\begin{array}{l}\text { Odds } \\
\text { Ratio }\end{array}$} & \multirow{2}{*}{$\begin{array}{c}95 \% \\
\text { confidence } \\
\text { intervals }\end{array}$} & \multirow{2}{*}{$\begin{array}{c}\text { p- } \\
\text { value }\end{array}$} \\
\hline & $\begin{array}{c}\text { \# with at least } 1 \\
\text { prescription }\end{array}$ & \# of nonusers & $\begin{array}{c}\text { \# with at lease } 1 \\
\text { prescription }\end{array}$ & \# of nonusers & & & \\
\hline \multicolumn{8}{|c|}{ all subjects aged $18-100$ years old } \\
\hline 5 years & 2588 & 18872 & 9435 & 69896 & 0.51 & $(0.29,0.90)$ & 0.021 \\
\hline 3 years & 2393 & 25117 & 8293 & 90607 & 0.58 & $(0.39,0.86)$ & 0.007 \\
\hline 1year & 1264 & 31959 & 4153 & 121708 & 0.60 & $(0.46,0.80)$ & $<.001$ \\
\hline 6 months & 822 & 35401 & 2619 & 123242 & 0.72 & $(0.56,0.93)$ & 0.012 \\
\hline 3 months & 533 & 35690 & 1652 & 124209 & 0.80 & $(0.64,1.01)$ & 0.056 \\
\hline \multicolumn{8}{|c|}{ subjects with aged $65-100$ years old } \\
\hline 5 years & 2243 & 10145 & 8242 & 37553 & 0.57 & $(0.31,1.07)$ & 0.079 \\
\hline 3 years & 2073 & 13600 & 7247 & 49098 & 0.63 & $(0.41,0.97)$ & 0.035 \\
\hline 1year & 1092 & 19000 & 3630 & 66182 & 0.64 & $(0.48,0.88)$ & 0.005 \\
\hline 6 months & 706 & 19386 & 2282 & 67530 & 0.72 & $(0.55,0.95)$ & 0.021 \\
\hline 3 months & 461 & 19631 & 1450 & 68362 & 0.83 & $(0.65,1.07)$ & 0.147 \\
\hline \multicolumn{8}{|c|}{ subjects with aged $18-64$ years old } \\
\hline 5 years & 345 & 8727 & 1193 & 32344 & 0.36 & $(0.08,1.67)$ & 0.193 \\
\hline 3 years & 320 & 11517 & 1046 & 41508 & 0.45 & $(0.15,1.34)$ & 0.152 \\
\hline 1year & 172 & 15959 & 524 & 55525 & 0.53 & $(0.25,1.11)$ & 0.090 \\
\hline 6 months & 116 & 16015 & 336 & 55713 & 0.82 & $(0.46,1.48)$ & 0.520 \\
\hline 3 months & 72 & 16059 & 201 & 55848 & 0.73 & $(0.43,1.26)$ & 0.262 \\
\hline \multicolumn{8}{|c|}{ male subjects } \\
\hline 5 years & 1185 & 11697 & 4175 & 43446 & 0.48 & $(0.19,1.24)$ & 0.131 \\
\hline 3 years & 1085 & 15145 & 3673 & 54675 & 0.57 & $(0.30,1.08)$ & 0.085 \\
\hline 1year & 563 & 20298 & 1799 & 70685 & 0.59 & $(0.38,1.91)$ & 0.016 \\
\hline 6 months & 366 & 20495 & 1095 & 71389 & 0.70 & $(0.47,1.05)$ & 0.087 \\
\hline 3 months & 237 & 20624 & 660 & 71824 & 0.80 & $(0.56,1.13)$ & 0.203 \\
\hline \multicolumn{8}{|c|}{ female subjects } \\
\hline 5 years & 1403 & 7175 & 5260 & 26450 & 0.52 & $(0.25,1.08)$ & 0.080 \\
\hline 3 years & 1308 & 9972 & 4621 & 35931 & 0.59 & $(0.35,0.98)$ & 0.042 \\
\hline 1year & 701 & 14661 & 2354 & 51023 & 0.61 & $(0.42,0.89)$ & 0.009 \\
\hline 6 months & 456 & 14906 & 1523 & 51854 & 0.73 & $(0.52,1.01)$ & 0.056 \\
\hline 3 months & 296 & 15066 & 992 & 52385 & 0.80 & $(0.60,1.07)$ & 0.136 \\
\hline
\end{tabular}

$\mathrm{p}=0.079)$ in people aged 65 years old or older. The comparison of estimated ORs between males and females was similar (males: $\mathrm{OR}=0.48,95 \% \mathrm{CI}=0.19 \sim 1.24$, $\mathrm{p}=0.131$; females: $\mathrm{OR}=0.52,95 \% \mathrm{CI}=0.25 \sim 1.08, \mathrm{p}=0.080$ ).

When considering different duration of selective COX-2 inhibitor usages prior to the index date, the ORs increased from 0.51 (95\% $\mathrm{CI}=0.29 \sim 0.90, \mathrm{p}=0.021)$ of 5 year-usage to $0.80(95 \% \mathrm{CI}=0.64 \sim 1.01, \mathrm{p}=0.056)$ of 3 month-usage. Significant differences appeared with the 6-month, 1-year, 3-year and 5-year usages. For the older age group (age $>=65$ years old), the ORs increased from $0.57(95 \% \mathrm{CI}=0.31 \sim 1.07, \mathrm{p}=0.079)$ for 5 year-usage to 0.83 (95\% $\mathrm{CI}=0.65 \sim 1.07, \mathrm{p}=0.147$ ) for 3 month-usage. Only the usages of 3-years, 1-year and 6-months were shown to be statistically significant. Although the younger age group (aged 18-64) had smaller ORs from
$0.36(95 \% \mathrm{CI}=0.08 \sim 1.67, \mathrm{p}=0.193)$ for 5 year-usage to 0.73 (95\% CI=0.43 1.26, $\mathrm{p}=0.262$ ) for 3 month-usage, none of these estimated effects were significant. The comparison of estimated ORs between males and females was also similar. Significant drug usage effects were found at 1-year usage by males (OR=0.59, 95\% $\mathrm{CI}=0.38 \sim 0.91, \mathrm{p}=0.016$ ) and at 3-year and 1-year usage by females (3-year: $\mathrm{OR}=0.59, \quad 95 \% \quad \mathrm{CI}=0.35 \sim 0.98$, $\mathrm{p}=0.042$; 1-year: $\mathrm{OR}=0.61,95 \% \mathrm{CI}=0.42 \sim 0.89, \mathrm{p}=0.009)$.

To investigate the risk reduction at various MPRs of drug usage for prior durations, the estimated ORs were computed by using indicator variables for at least $10 \%$ to $90 \%$ (in 10\% intervals) of MPRs at follow-up durations in 9 separate conditional logistic regressions with "no use" as the reference category. These estimated ORs with standard error of parameter estimate less than 0.45 
(equivalent to all cell sizes larger than 5) are plotted in Figure 2. The risk reduction curves, which consist of ORs, decrease as the MPRs increase, and all of the estimated ORs show protection effects $(\mathrm{ORs}<1)$. ORs showing significant protection effects are at $10 \%$ and $20 \%$ of 5 -year cumulative usage, at $10 \%$ to $40 \%$ of 3 -year usage, at $10 \%$ to $80 \%$ of 1 -year usage, and at $30 \%$ to $60 \%$ and $80 \%$ of 6 -month usage. Except for the 3-month curve, the other 4 curves (5-year, 3-year, 1-year and 6-month) are closer together. Figure 3 shows plots for subgroups of age (age $>=65$ and age $<65$ ) and gender (males and females). The ORs for the least $10 \%$ of usage were more heterogeneous in people with age less than 65 and in males.

For the sensitivity analyses (Table 3), using the 5-year follow-up group for the 3-year and 1-year analyses reveals similar estimates only with less statistical significance. When considering participants without any prior history of cardiovascular events, the estimated ORs are not very different.

\section{Discussion}

Potential chemopreventive benefits were investigated using a database of cancer patients, and a large database of Taiwanese patients. We were able to demonstrate a dose-response protective effect for selective COX-2 inhibitors, which was related to the occurrence of CRC in individuals.

Based on our results, the proportion of people prescribed at least one COX-2 inhibitor was not significantly different ( $\mathrm{p}=0.595$ ) between CRC patients and the control group. Usage of selective COX-2 inhibitors between the 2 groups was only different for cumulative DDD. This suggested a potential dose-response relationship for risk reduction. Significant reduction in risk regarding CRC was found for those taking selective COX-2 inhibitors over 6 months $(28 \%, \mathrm{OR}=0.72), 1$ year $(40 \%, \mathrm{OR}=0.60)$, 3 years $(42 \%, \mathrm{OR}=0.58)$ and 5 years $(49 \%$, OR $=0.51)$. In the group with subjects aged 65 or younger, there was a more pronounced reduction in risk (63\% following 5 years of use), however there was no statistical significance. Risk reduction was similar between males and females, and could even be observed at MPRs as low as $10 \%$. In terms of various MPRs (Figure 2), except for the 3-month curve, the other 4 curves (5-year, 3-year, 1-year and 6-month) are closer together. Given that all of the MPRs from 3-month were all not statistically significant, these results might suggest a potential minimum treatment period for chemopreventive effects. In addition, a U-shaped curve can be observed from female patients indicated the protection effects were not associated with increased MPRs. Future studies may look into the disappearance of protection trend by identifying common diseases requiring long-term medication treatment in females.

COX-2 has been found to be over-expressed in many cancers, including CRC [3]. Blockade of COX-2 would down-regulate its metabolic product, PGE2, thereby decreasing the risk of CRC [3]. Prostaglandin levels correlate with disease activity and are consequently correlated

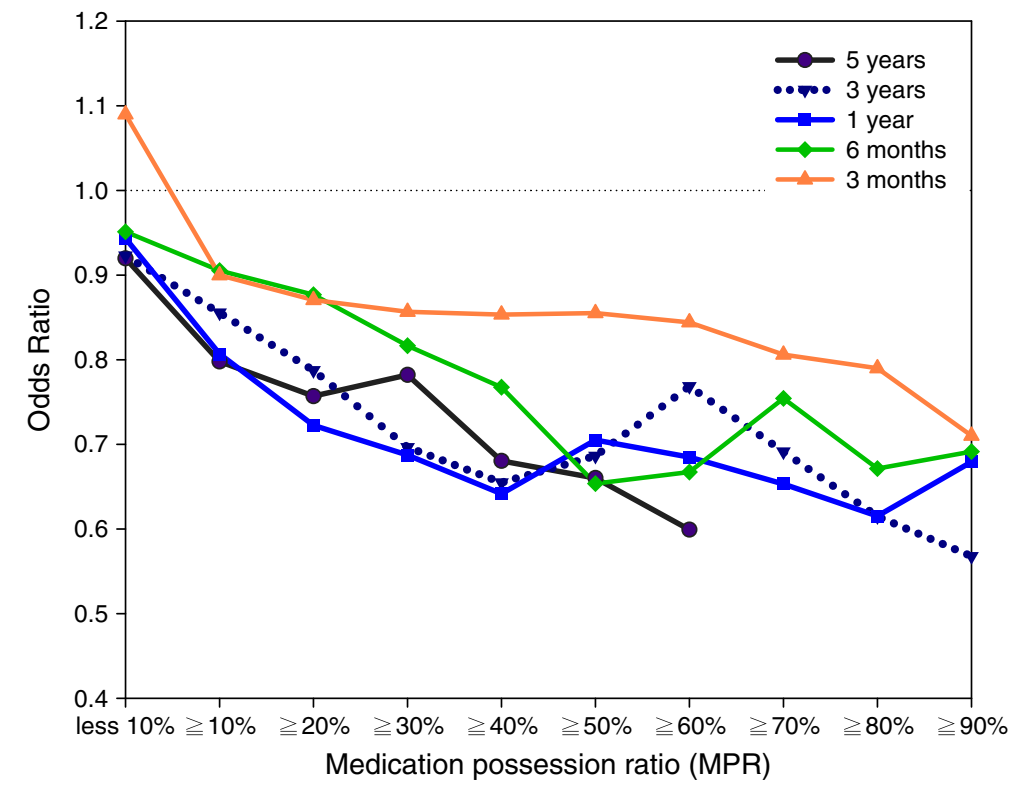

Figure 2 Odds ratios for developing colorectal cancer in different MPRs for selective COX-2 inhibitors. (Note: Significant odds ratios are at $10 \%$ and $20 \%$ of 5 -year cumulative usage, at $10 \%$ to $40 \%$ of 3 -year usage, at $10 \%$ to $80 \%$ of 1 -year usage, and at $30 \%$ to $60 \%$ and $80 \%$ of 6-month usage). 


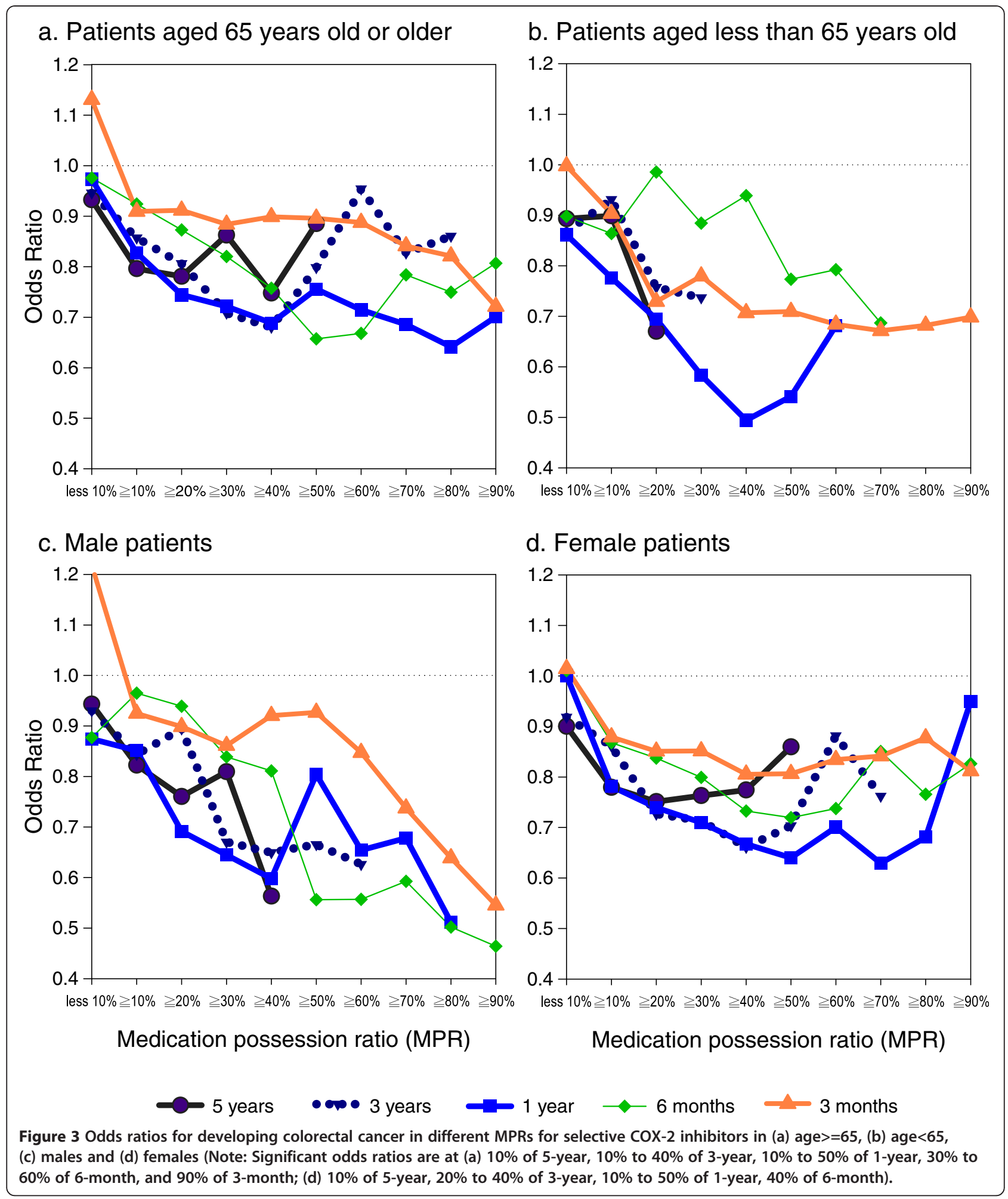

with COX expression. This is especially so for COX-2. Prostaglandins derived from COX-1 and COX-2 appear to play a protective role. Theoretically, NSAIDs and COX-2 inhibitors should be capable of inhibiting intestinal production of prostaglandins involved in tissue repair processes. However, previous research has demonstrated conflicting data in animal and clinical studies [3].

Patients administered celecoxib show reduction in size and number of adenomas [1]. Bertagnolli et al. [12] 
Table 3 Sensitivity analyses

\begin{tabular}{|c|c|c|c|c|c|c|c|}
\hline \multirow[t]{2}{*}{ Sensitivity analysis } & \multicolumn{2}{|c|}{ Colon cancer patients } & \multicolumn{2}{|l|}{ Controls } & \multirow{2}{*}{$\begin{array}{l}\text { Odds } \\
\text { Ratio }\end{array}$} & \multirow{2}{*}{$\begin{array}{l}95 \% \\
\text { confidence } \\
\text { intervals }\end{array}$} & \multirow{2}{*}{$\begin{array}{l}\mathrm{p}- \\
\text { value }\end{array}$} \\
\hline & $\begin{array}{l}\text { \# with at least } \\
1 \text { prescription }\end{array}$ & $\begin{array}{l}\text { \# of } \\
\text { nonusers }\end{array}$ & $\begin{array}{l}\text { \# with at least } \\
1 \text { prescription }\end{array}$ & $\begin{array}{l}\text { \# of } \\
\text { nonusers }\end{array}$ & & & \\
\hline \multicolumn{8}{|l|}{ 5-year follow-up prior to index date } \\
\hline $\begin{array}{l}\text { main analysis: maximum numbers of participants in different } \\
\text { years of follow-up }\end{array}$ & 2588 & 18872 & 9435 & 69896 & 0.51 & $(0.29,0.90)$ & 0.021 \\
\hline $\begin{array}{l}\text { using the same 5-year follow-up group for 3-year and 1-year } \\
\text { analyses }\end{array}$ & 2588 & 18872 & 9435 & 69896 & 0.51 & $(0.29,0.90)$ & 0.021 \\
\hline $\begin{array}{l}\text { participants without any occurance of myocardial infarction } \\
\text { or congestive heart failure }\end{array}$ & 2048 & 17238 & 7584 & 64687 & 0.57 & $(0.30,1.08)$ & 0.085 \\
\hline patients without any occurance of peptic ulcer disease & 1112 & 12374 & 4597 & 52859 & 0.61 & $(0.19,1.97)$ & 0.412 \\
\hline patients with any occurance of peptic ulcer disease & 1476 & 6498 & 4838 & 17037 & 0.31 & $(0.08,1.19)$ & 0.089 \\
\hline patients without any occurance of colon or rectal polyps & 2520 & 18447 & 9432 & 69895 & 0.55 & $(0.30,1.98)$ & 0.044 \\
\hline \multicolumn{8}{|l|}{ 3-year follow-up prior to index date } \\
\hline $\begin{array}{l}\text { main analysis: maximum numbers of participants in different } \\
\text { years of follow-up }\end{array}$ & 2393 & 25117 & 8293 & 90607 & 0.58 & $(0.39,1.86)$ & 0.007 \\
\hline using the same 5-year follow-up group for 3-year analysis & 2376 & 19084 & 8489 & 70842 & 0.60 & $(0.40,0.89)$ & 0.011 \\
\hline $\begin{array}{l}\text { participants without any occurance of myocardial infarction } \\
\text { or congestive heart failure }\end{array}$ & 1990 & 23458 & 7001 & 85573 & 0.61 & $(0.39,0.94)$ & 0.026 \\
\hline patients without any occurance of peptic ulcer disease & 1190 & 17857 & 4737 & 74165 & 0.71 & $(0.37,1.36)$ & 0.304 \\
\hline patients with any occurance of peptic ulcer disease & 1203 & 7260 & 3556 & 16442 & 0.49 & $(0.20,1.20)$ & 0.117 \\
\hline patients without any occurance of colon or rectal polyps & 2316 & 18671 & 8488 & 70841 & 0.61 & $(0.40,0.91)$ & 0.016 \\
\hline \multicolumn{8}{|l|}{ 1-year follow-up prior to index date } \\
\hline $\begin{array}{l}\text { main analysis: maximum numbers of participants in different } \\
\text { years of follow-up }\end{array}$ & 1264 & 31959 & 4153 & 121708 & 0.60 & $(0.46,0.80)$ & $<.001$ \\
\hline $\begin{array}{l}\text { using the same 5-year follow-up group for 3-year and 1-year } \\
\text { analyses }\end{array}$ & 1247 & 20213 & 4380 & 74951 & 0.61 & $(0.46,0.81)$ & 0.001 \\
\hline $\begin{array}{l}\text { participants without any occurance of myocardial infarction } \\
\text { or congestive heart failure }\end{array}$ & 1139 & 33696 & 3807 & 118187 & 0.59 & $(0.43,0.79)$ & 0.001 \\
\hline patients without any occurance of peptic ulcer disease & 765 & 28501 & 2951 & 111326 & 0.79 & $(0.54,1.15)$ & 0.227 \\
\hline patients with any occurance of peptic ulcer disease & 499 & 3458 & 1202 & 10382 & 0.56 & $(0.17,1.85)$ & 0.340 \\
\hline patients without any occurance of colon or rectal polyps & 1216 & 19797 & 4379 & 74951 & 0.61 & $(0.46,0.81)$ & 0.001 \\
\hline \multicolumn{8}{|l|}{ 6-month follow-up prior to index date } \\
\hline $\begin{array}{l}\text { main analysis: maximum numbers of participants in different } \\
\text { years of follow-up }\end{array}$ & 822 & 35401 & 2619 & 123242 & 0.72 & $(0.56,0.93)$ & 0.012 \\
\hline $\begin{array}{l}\text { using the same 5-year follow-up group for 3-year and 1-year } \\
\text { analyses }\end{array}$ & 806 & 20654 & 2747 & 76584 & 0.72 & $(0.56,0.93)$ & 0.013 \\
\hline $\begin{array}{l}\text { participants without any occurance of myocardial infarction } \\
\text { or congestive heart failure }\end{array}$ & 744 & 34091 & 2411 & 119583 & 0.70 & $(0.53,0.91)$ & 0.009 \\
\hline patients without any occurance of peptic ulcer disease & 491 & 28775 & 1855 & 112422 & 0.95 & $(0.68,1.33)$ & 0.777 \\
\hline patients with any occurance of peptic ulcer disease & 331 & 6626 & 764 & 10820 & 0.67 & $(0.24,1.88)$ & 0.443 \\
\hline patients without any occurance of colon or rectal polyps & 786 & 20227 & 2747 & 76583 & 0.71 & $(0.55,0.92)$ & 0.009 \\
\hline \multicolumn{8}{|l|}{ 3-month follow-up prior to index date } \\
\hline $\begin{array}{l}\text { main analysis: maximum numbers of participants in different } \\
\text { years of follow-up }\end{array}$ & 533 & 35690 & 1652 & 124209 & 0.80 & $(0.64,1.01)$ & 0.056 \\
\hline $\begin{array}{l}\text { using the same 5-year follow-up group for 3-year and 1-year } \\
\text { analyses }\end{array}$ & 521 & 20939 & 1721 & 77610 & 0.80 & $(0.64,1.01)$ & 0.057 \\
\hline $\begin{array}{l}\text { participants without any occurance of myocardial infarction } \\
\text { or congestive heart failure }\end{array}$ & 480 & 34355 & 1502 & 120492 & 0.78 & $(0.61,0.98)$ & 0.036 \\
\hline patients with any occurance of peptic ulcer disease & 209 & 6748 & 511 & 11073 & 0.76 & $(0.31,1.85)$ & 0.550 \\
\hline patients without any occurance of colon or rectal polyps & 507 & 20506 & 1721 & 77609 & 0.79 & $(0.63,0.99)$ & 0.038 \\
\hline
\end{tabular}


studied patients with prior history of adenomas, and reported that the risk of developing one or more adenomas in 3 years was reduced by $33 \%$ in patients treated with $200 \mathrm{mg}$ of celecoxib. Risk was reduced by $45 \%$ in patients given 400mg of celecoxib as compared with the placebo group. The Prevention of Colorectal Sporadic Adenomatous Polyps (PreSAP) trial [13] studied similar patients, and showed a $36 \%$ reduction in adenoma recurrence and $51 \%$ reduction in advanced adenoma in patients taking $400 \mathrm{mg}$ of celecoxib once a day. A metaanalysis [7] of the two clinical trials [12,13] showed a $44 \%$ reduction in the recurrence of any adenoma, and a $55 \%$ reduction in advanced adenoma during 3 years of follow-up. For rofecoxib, the Adenomatous Polyp Prevention on Vioxx (APPROVe) trial [14] identified that adenoma recurrence was less frequent $(R R=0.76)$ in the rofecoxib group. Chemopreventive effects were more pronounced in the first year $(R R=0.65)$ than in the subsequent two years $(R R=0.81)$ [3]. From that study, the 3year risk reduction was estimated at $42 \%(\mathrm{OR}=0.58$, $95 \% \mathrm{CI}=0.39 \sim 0.86$ ), indicating a similar protective effect regardless of CRC occurrence. The median ages of subjects in the two celecoxib studies were 61 [13] and 59 [12] years. In our study, we observed a 55\% risk reduction in people younger 65 , decreasing further to $37 \%$ for those 65 and older.

To date, no reports have been published investigating the chemopreventive roles of non-aspirin NSAIDs, especially selective COX-2 inhibitors, in general populations [7]. An earlier study [15] investigating the effects of aspirin and other NSAIDs on risk reduction revealed an OR of 0.76 (95\% CI $=0.58 \sim 1.00)$ for colon cancer, and $0.75(95 \% \mathrm{CI}=0.49 \sim 1.14)$ for a 3 -year follow-up with at least seven prescriptions.

Selective COX-2 inhibitors are associated with increased risk of cardiovascular events $[7,16]$. The withdrawal of rofecoxib [14], along with the early termination of the Bertagnolli [12] and Arber [13] studies were all because of more serious adverse cardiovascular adverse events. Selective COX-2 inhibitors have also been associated with gastrointestinal symptoms, primarily as a result of the inhibition of mucosal protective prostaglandins $[3,4,16]$. The prevalence of gastrointestinal events was greater in the celecoxib groups of the Arber Study. Additionally, renal disease or hypertension was significantly higher in the celecoxib group of the Arber study, and also in one of the two celecoxib groups of the Bertagnolli study [7]. In our study, we did not include adverse events as outcomes. During follow-up, we found that overall, there was a greater number of cancer patients using COX-2 inhibitors, however the average number was lower than those seen for the control group. This is possibly because of adverse events, therefore administration of medication has to be discontinued. We investigated patients without any occurrence of myocardial infarction or congestive heart failure and peptic ulcer disease. It was found that the estimates of risk reduction were not largely different in patients without cardiovascular events. Therefore, the occurrence of cardiovascular events might not have effect on the association of COX-2 inhibitors and CRC. In terms of peptic ulcer disease, greater increases in the risk reduction were observed in patients with occurrence of peptic ulcer disease. However, in this study we did not have enough sample size to provide sufficient statistical evidence.

We have included both refecoxib and celecoxib in the analysis. Since rofecoxib was withdrawn in 2004, the study results may not directly reflect the effect of the current available COX-2 inhibitor (celecoxib).

The ICD-9 codes of 140-208 are sometimes provided by the Taiwan NHI program for cancer-screening purposes. The result of this is that the incidences of cancer can be greatly overestimated. In our study, CRC patients were identified by linking their encrypted personal identification number to the Registry for Catastrophic Illness patients with ICD9 code 153-154. For patients to be in the Registry for Catastrophic Illness, their medical records need to be reviewed so that they can qualify for $100 \%$ reimbursement of disease-related medical expenses. Our database comprised approximately $90 \%$ of the Taiwan cancer incidence registry. A possible reason why patients might not appear in the catastrophic illness registry of the NHI program may include short period between diagnosis of CRC and death. These identified patients were excluded from the study. Therefore, we believe that $90 \%$ of CRC patients in the Catastrophic Illness Registry was a reasonable representation of CRC patients in Taiwan.

Our study also has limitations on some key confounders of CRC, including familial adenomatous polyposis [17], calcium [18], folate, methionine and alcohol intake [19] as well as exercise, obesity and smoking habit [7]. These factors were not recorded in the NHI database, and might reduce the estimates of risk reduction, if they were included in regression analyses. For a given participant, the usage of selective COX-2 inhibitors might have been affected by co-prescriptions of other NSAIDs. To adjust for this situation, the conditional logistic regressions were also conducted with two MPR covariates for tNSAIDs and preferential COX-2.

The database used did not include information for over-the-counter use. Hence, some underestimation of the NSAIDs used may have occurred. Because the Taiwan NHI program provides comprehensive medication coverage, any drug use not recorded in the database would be limited to short-term relief of symptoms, and the effect on the study results is therefore limited. 
It has been speculated that the development of an adenoma into CRC may take as long as 10-15 years [7]. Given that outcomes can only be assessed by colonoscopy, there may be some false negatives in the control group. The control group included people without CRC or other cancers before and after the index dates. This was to prevent possible misclassification due to late diagnosis of cancers. In the sensitivity analysis, we also investigated patients without any occurrence of colon and rectal polyps. It was found that the estimates of risk reduction were not largely different from the main analysis. Therefore, the effect on the association of COX-2 inhibitors and CRC might be limited.

\section{Conclusion}

Few studies have focused on the chemopreventive effects of selective COX-2 inhibitors on CRC in the general population. The results support the chemopreventive role of selective COX-2 inhibitors in CRC. Risk reduction occurred after 6 months, 3 years and 5 years of continual use of the drugs. Additionally, the frequencies of use for COX-2 inhibitors from 1-5 years may be as low as $10 \%$ of MPRs to achieve at least $10 \%$ risk reduction with respect to developing CRC. Given limited reports from individuals with no increased risk of CRC, our results provide information in the general population.

\section{Abbreviations \\ COX-2: Cyclooxygenase-2; CRC: Colorectal cancer; NHIRD: Health Insurance Research Database; NSAIDs: Non-steroidal anti-inflammatory drugs; MPR: Medication possession ratio; tNSAID: Traditional NSAID.}

\section{Competing interests}

The authors declare that they have no competing interests.

\section{Authors' contributions}

YHY performed statistical analyses and drafted the manuscript. YHKY and CLL participated in the study design, and helped to draft the manuscript. PSH and YCK provided important inputs to the manuscript. All authors read and approved the final manuscript.

\section{Acknowledgements}

This study has been made possible by the following financial support: National Science Council (NSC 98-2314-B-037 -060-MY2), Department of Health, Executive Yuan (DOH100-TD-C-111-002) and Center of Excellence for Environmental Medicine, Kaohsiung Medical University.

\footnotetext{
Author details

${ }^{1}$ School of Pharmacy, College of Pharmacy, Kaohsiung Medical University, Kaohsiung, Taiwan. ${ }^{2}$ Cancer Center, Kaohsiung Medical University Hospital, Kaohsiung, Taiwan. ${ }^{3}$ Institute of Clinical Pharmacy and Pharmaceutical Sciences, Health Outcome Research Center, National Cheng Kung University, Tainan, Taiwan. ${ }^{4}$ Department of Oral Hygiene, College of Dental Medicine, Kaohsiung Medical University, Kaohsiung, Taiwan. ${ }^{5}$ Center of Excellence for Environmental Medicine, Kaohsiung Medical University, Kaohsiung, Taiwan. ${ }^{6}$ Graduate Institute of Clinical Medical Science, China Medical University, Taichung, Taiwan. ${ }^{7}$ Enviroment-Omics-Disease Reserach Center, China Medical University Hospital, Taichung, Taiwan.
}

\section{References}

1. Moreira L, Castells A: Cyclooxygenase as a target for colorectal cancer chemoprevention. Curr Drug Targets 2011, 12(13):1888-1894.

2. In Cancer registry annual report 2008. Edited by Bureau of Health Promotion DoH, Executive Yuan. Taiwan: R.O.C; 2011.

3. Lanas A, Ferrandez A: NSAIDs and the colon. Curr Opin Gastroenterol 2009, 25(1):44-49.

4. Sarkar FH, Adsule S, Li Y, Padhye S: Back to the future: COX-2 inhibitors for chemoprevention and cancer therapy. Mini Rev Med Chem 2007, 7(6):599-608.

5. Brown JR, DuBois RN: COX-2: a molecular target for colorectal cancer prevention. J Clin Oncol 2005, 23(12):2840-2855.

6. Antman EM, Bennett JS, Daugherty A, Furberg C, Roberts H, Taubert KA: Use of nonsteroidal antiinflammatory drugs: an update for clinicians: a scientific statement from the American Heart Association. Circulation 2007, 115(12):1634-1642

7. Cooper K, Squires H, Carroll C, Papaioannou D, Booth A, Logan RF, Maguire C, Hind D, Tappenden P: Chemoprevention of colorectal cancer: systematic review and economic evaluation. Health Technol Assess 2010, 14(32):1-206.

8. Ray WA, MacDonald TM, Solomon DH, Graham DJ, Avorn J: COX-2 selective non-steroidal anti-inflammatory drugs and cardiovascular disease. Pharmacoepidemiol Drug Saf 2003, 12(1):67-70

9. WHO Collaborating Centre for Drug Statistics Methodology, ATC/DDD Index Oslo, Norway: World Health Organization; 2012. http://www.whocc.no/ atc_ddd_index.

10. Deyo RA, Cherkin DC, Ciol MA: Adapting a clinical comorbidity index for use with ICD-9-CM administrative databases. J Clin Epidemio/ 1992, 45(6):613-619.

11. Quan H, Sundararajan V, Halfon P, Fong A, Burnand B, Luthi JC, Saunders $L D$, Beck CA, Feasby TE, Ghali WA: Coding algorithms for defining comorbidities in ICD-9-CM and ICD-10 administrative data. Med Care 2005, 43(11):1130-1139.

12. Bertagnolli MM, Eagle CJ, Zauber AG, Redston M, Solomon SD, Kim K, Tang J, Rosenstein RB, Wittes J, Corle D, et al: Celecoxib for the prevention of sporadic colorectal adenomas. N Engl J Med 2006, 355(9):873-884.

13. Arber N, Eagle CJ, Spicak J, Racz I, Dite P, Hajer J, Zavoral M, Lechuga MJ, Gerletti $P$, Tang J, et al: Celecoxib for the prevention of colorectal adenomatous polyps. N Engl J Med 2006, 355(9):885-895.

14. Baron JA, Sandler RS, Bresalier RS, Quan H, Riddell R, Lanas A, Bolognese JA, Oxenius B, Horgan $K$, Loftus $S$, et al: A randomized trial of rofecoxib for the chemoprevention of colorectal adenomas. Gastroenterology 2006, 131(6):1674-1682.

15. Langman MJ, Cheng KK, Gilman EA, Lancashire RJ: Effect of antiinflammatory drugs on overall risk of common cancer: case-control study in general practice research database. BMJ 2000, 320(7250):1642-1646.

16. Rostom A, Dube C, Lewin G, Tsertsvadze A, Barrowman N, Code C, Sampson M, Moher D: Nonsteroidal anti-inflammatory drugs and cyclooxygenase-2 inhibitors for primary prevention of colorectal cancer: a systematic review prepared for the U.S. Preventive Services Task Force. Ann Intern Med 2007, 146(5):376-389.

17. Johns LE, Houlston RS: A systematic review and meta-analysis of familial colorectal cancer risk. Am J Gastroenterol 2001, 96(10):2992-3003.

18. Carroll C, Cooper K, Papaioannou D, Hind D, Pilgrim H, Tappenden P: Supplemental calcium in the chemoprevention of colorectal cancer: a systematic review and meta-analysis. Clin Ther 2010, 32(5):789-803.

19. Giovannucci E, Stampfer MJ, Colditz GA, Rimm EB, Trichopoulos D, Rosner BA, Speizer FE, Willett WC: Folate, methionine, and alcohol intake and risk of colorectal adenoma. J Natl Cancer Inst 1993, 85(11):875-884.

doi:10.1186/1471-2407-12-582

Cite this article as: Yang et al:: The role of chemoprevention by selective cyclooxygenase- 2 inhibitors in colorectal cancer patients - a populationbased study. BMC Cancer 2012 12:582. 